ENTREPRENEURSHIP AND SUSTAINABILITY ISSUES

ISSN 2345-0282 (online) http://jssidoi.org/jesi/

2021 Volume 8 Number 4 (June)

http://doi.org/10.9770/jesi.2021.8.4(44)

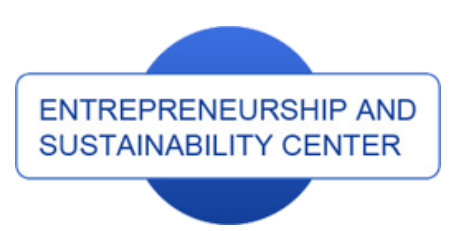

Publisher

http://jssidoi.org/esc/home
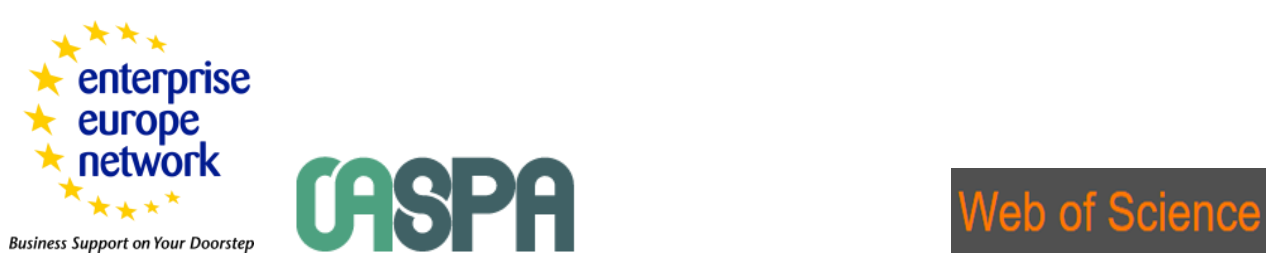

Clarivate

Analytics

\title{
THE GROWTH OF THE COUNTRY'S ECONOMIC SECURITY LEVEL BASED ON THE INVESTMENT INFRASTRUCTURE DEVELOPMENT PROJECTS
}

\author{
Lidiia Karpenko $^{1 *}$, Mykola Izha ${ }^{2}$, Iryna Chunytska ${ }^{3}$, Andrii Maiev ${ }^{4}$, Kateryna Hunko 5 \\ ${ }^{1,2,4}$ Odessa Regional Institute for Public Administration of the National Academy for Public Administration under the \\ President of Ukraine, Genuezka, 22, 65009, Odessa, Ukraine \\ ${ }^{3,5}$ University of the State Fiscal Service of Ukraine, 31, Universytetska str., 08201 Irpin, Ukraine \\ E-mails: ${ }^{{ }^{*}}$ karpenko_l@ $@$ ukr.net (Corresponding author)
}

Received 10 March 2021; accepted 6 May 2021; published 30 June 2021

\begin{abstract}
The article is dedicated to the question of providing investment development of the national infrastructure and adherence to the economic security level growth conditions. The authors determined the role of investments and the project orders in the development of the national infrastructure and formation of the national reforms investment support policy. While conducting the research, they built a model of investment interest simulation and scenarios of investors' behavior, and analyzed the application of Monte Carlo technique regarding the investment projects. They developed a procedure model of Monte Carlo technique use for assessment of the investment projects at the given level of economic security. They generalized the methodological approaches to the practical application of Monte Carlo technique and method of historic simulations in assessment and minimizing the risks of the investment projects, which are carried out in the infrastructure industry of the country's economy. The researchers studied the peculiarities of application of Monte Carlo technique and simulations method during the assessment and minimizing the risks of investment projects in coordinates of economic security. They offered conceptual foundations of probability and statistical assessment of the investment projects risks concerning the country's infrastructure development in the given interval of economic security. They determined and provided a step-by-step order for calculating the expected cost NVP of investment projects within the national economic space and coordinates of economic security.
\end{abstract}

Keywords: economic security; national infrastructure; investment provision of development; capital investment project; Monte Carlo simulation analysis; risks of capital investment projects

Reference to this paper should be made as follows: Karpenko, L., Izha, M., Chunytska, I., Maiev, A., Hunko, K. 2021. The growth of the country's economic security level based on the investment infrastructure development projects. Entrepreneurship and Sustainability Issues, 8(4), 713-729. http://doi.org/10.9770/jesi.2021.8.4(44)

JEL Classifications: C21, E22, E60 


\section{ENTREPRENEURSHIP AND SUSTAINABILITY ISSUES}

ISSN 2345-0282 (online) http://jssidoi.org/jesi/

2021 Volume 8 Number 4 (June)

http://doi.org/10.9770/jesi.2021.8.4(44)

\section{Introduction}

The development of the country's infrastructure is one of the most important priorities for modernization of the modern economy and provision of economic security as the infrastructure contributes to the formation of the basis for effective implementation of the economic processes and connectivity between business entities. Infrastructure has always been of strategic importance not only for the regions but also the state in general, providing the reproductive process in all spheres of society's living environment and setting the prerequisites and foundations for the development of the economic activity, focused at the reasonable transformation of the economic environment and growth of the national economic security level. As of today, the development of the country's infrastructure has international importance due to the modernity of the globalization and European integration processes.

The development of the country's modern infrastructure and its economic security is affected by many factors, among which are socio-economic and ecological, global and political processes. At the same time, investments are still regarded as the foundation of the country's infrastructure development. Upon their nature, they can have different directness and area of application. Nevertheless, the non-systemic and inconsistent financing of the development of the national infrastructure, dated institutional provision of the national investment policy, and imperfection of the tools for disclosing the infrastructure potential, fluctuations in the volume and speed of investments attraction, make it necessary to actualize the theoretical and methodological framework and practical frame on investment provision of development of the country's infrastructure and advancement of the economic security level. The urgency of this problem and the dynamic changes of the investment prerequisites of the country's infrastructure development require constant research of theoretical and applied foundations of investment provision of sustainable growth.

\section{Literature review}

The shortening of differentiation at the levels of the country's social and economic development, activation of investment activity, promotion of efficient funds handling, strengthening of the national economy, and alignment of economic development priorities with the corresponding national priorities, raise the need for the definition of the categorical system of infrastructure's investment development, and provision of economic security.

Such researchers as (Ackert, Deaves, 2010; Chambers et. al., 1982) carry out a profound analysis of modern notional loading of the term of infrastructure and its security parameters at different levels and stages of social production. When analyzing modern approaches to the definition and classification of infrastructure, they mention that their main disadvantage is that to identify its elements, it is necessary to consider as a system only the country's economy in general.

A range of modern researchers (Potts, 2002; Wilmott, 2009) concretize the economic nature of infrastructure and expediency of investing in it, and come to a conclusion that its most significant feature and factor of its security under conditions of the market economy is the role in the provision of general prerequisites of the reproduction process and general conditions of growth of public production and, hence, economic progress at an expense of implementation of the national investment projects.

When describing modern infrastructure, many researchers (Alkaraan and Northcott, 2006; Arnold, 2010; Campell, 2003) mention versatility of the components, which are included in its structure and carry out specific, inherent only to them, functions, which in complex provide the implementation of the objective function of the infrastructure and form stable long-term security. At the same time, an especially important place is given to the need for the provision of the objective-directedness of the infrastructure operation and close interdependence of its elements, performing diverse functions, which is an obligatory condition of its efficient operation and implementation of socio-economic and investment processes at a scale of the country. 


\section{ENTREPRENEURSHIP AND SUSTAINABILITY ISSUES}

ISSN 2345-0282 (online) http://jssidoi.org/jesi/

2021 Volume 8 Number 4 (June)

http://doi.org/10.9770/jesi.2021.8.4(44)

Gitman and Joehnk (2008) consider the national infrastructure to have three main contours, put into each other the infrastructure of sense of life, the infrastructure of life support, and infrastructure of development. Along with this, the infrastructure of development falls into five main components: transport, customs, informational (connection), financial, and commercial. Each of them is characterized by the economic and investment security aspects.

At a modern stage, the researchers-economists more often consider it as an integrant factor of economic development (Barnett et al., 2015; Jackson, 2010; Mazzanti et al., 2020), accordingly, at the national level of provision of "efficient" infrastructure formation, required for both the advancement of the economy of the country with a low level of development and provision of the national high level of economic security.

\section{Research Methodology and Data}

We will form the methodological concepts of the national infrastructure investment development and adherence to the conditions of the economic security level growth based on the following principles and approaches, namely: 1) the concept of investment provision of infrastructure development is directed at formation of the national investment policy, which - at an expense of attraction and use of investments (including) - provides for the development of the country's general infrastructure, based on the advancement of its investment security for investment attractiveness improvement; 2) the concept of concessionary investment is a long-term capital investment in the objects of the national form of management, which upon the concessionary agreement expiry fall under the ownership of the state; the problematics of efficiency determination from concessionary investment; contradiction in calculating the sizes of concessionary payments according to the relevant normative-legal acts; the procedure of decrease in the size of the concessionary payment for a sum of put amortization costs for renovation of the main funds, received in concession; one hasn't determined the intervals for the expert estimation of the integral property complexes; 3) crowdfunding financing and investment of the national projects. To hold crowdfunding, one uses the corresponding electronic resources, including the application of specializes servers.

Through the use of Internet resources, the crowdfunding technology makes it possible to significantly expand the scope of people who want to take part in the financing of the national investment projects. Such technology makes it possible to remove a big number of intermediaries, participating in the regular project financing schemes. The crowdfunding platform acts as the only intermediary; 4) the conceptual approach to the provision of investment support for the development of the country's infrastructure, which provides for the conduction of the five-stage research according to the given hypotheses, concerning the interdependence between the socio-economic condition of the country and the development of its infrastructure, investment attractiveness, and the investment policy (Wickson at al 2006). Such a conceptual approach to investment provision of the national infrastructure development is the foundation of the infrastructure complexes' capability to self-development based on a specific level of socio-economic development.

\section{Results}

Effective development of the country's infrastructure depends on the application of the latest approaches to the determination, formation, and attraction of investments, which determine success in achieving stable social and economic development of the country, which, in its turn, makes the prerequisites for the improvement of the investment national attractiveness, and activation of investment activity. The increase in performance of investment activity is one of the main prerequisites for stabilization and development of the national economy. Nevertheless, under the condition of uncertainty, business entities face the deficit of investment resources, threatening the level of economic security. When building the concept for the investment provision of the country's infrastructure development, the risk assessment appears to be an extremely important component for 
developing the applied methodological regulations on control and prevention of the cases of economic security conditions infringement. We think it makes sense to consider the quantitative risk assessment of the investment projects, regarding the country's infrastructure development, through the prism of the theoretically-practical application of the simulation methods, grounding on Monte Carlo simulation analysis and resides in the multiple perceptions of the course of computation of the efficiency index of the investment project, according to the adopted efficiency assessment method (Yin 2009). Herewith, in most cases, it is clear current value and internal rate of return. The conditional model of investment interest simulation and investors' behavior scenarios are given in Fig. 1.

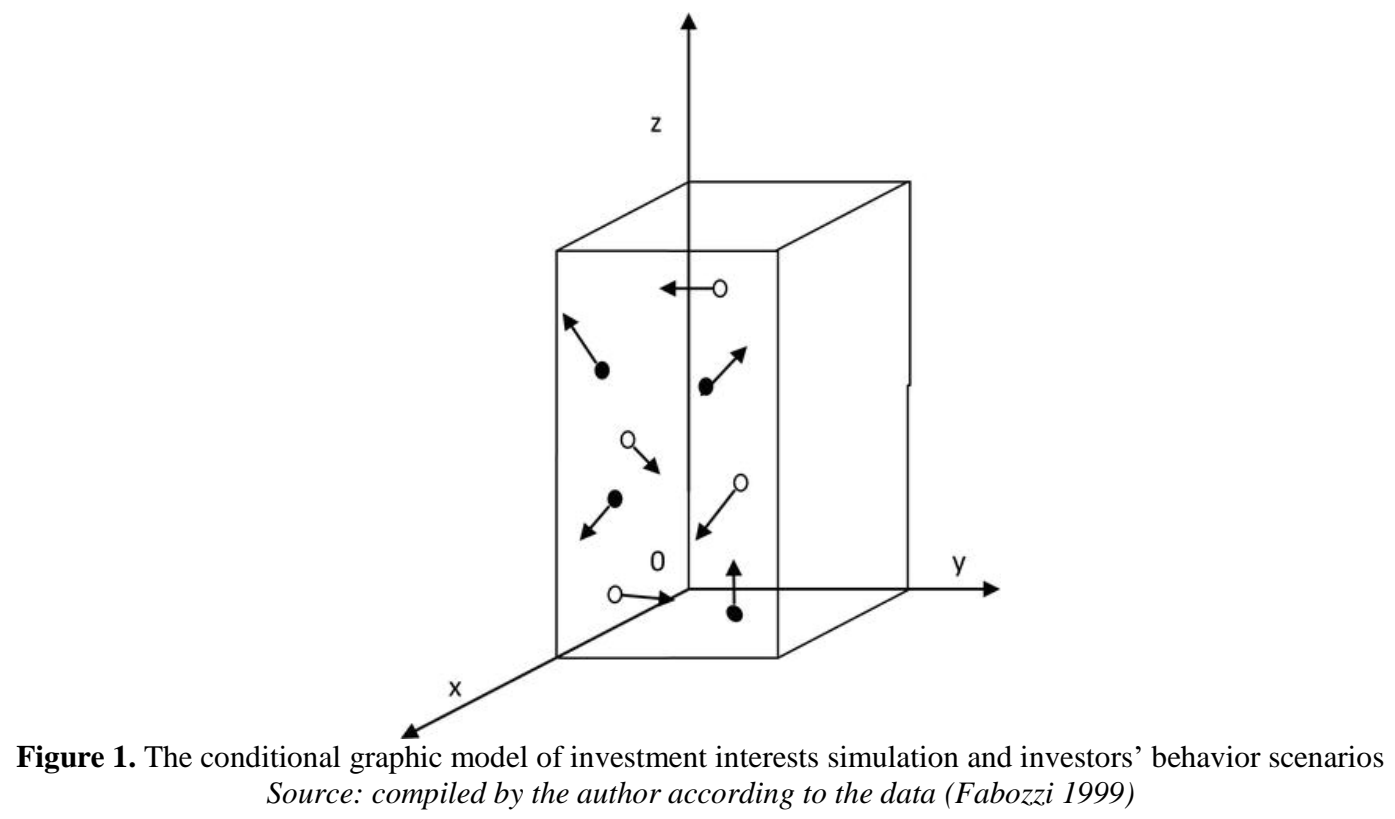

This is precisely why when studying the peculiarities of Monte Carlo simulation method application during the assessment of the risks of the investment projects, regarding the development of the country's infrastructure and control over the level of economic security, one faces a need to clearly determine the process and principles of its conduction, which will make it possible to avoid the conduction of an exhaustive review of all possible options in the future, but to use a representative sample of scenarios. Thus, when managing the risks, the simulation models can provide important sources of information sources for the organization both in terms of determining the new investment strategies and adoption of new corporate strategies (Lewis, 1999). The process of planning a strategy or optimization of the latter at the organizational level grounds on the analysis of internal and external risk factors as well as the possibility of their achievement.

The algorithm of Monte Carlo method grounds on the following steps (Fishman 1996):

Step 1: Development of a parametric model, $y=f\left(x_{1}, x_{2}, \ldots, x_{q}\right)$;

Step 2: Generation of a random input set of data, $x_{i 1}, x_{i 2}, \ldots, x_{i q}$;

Step 3: Effective calculations and memorization of results as $y_{i}$;

Step 4: Repetition of Step 2 and Step 3 for $i=1$ to $m(m \geq 1000)$;

Step 5: Analysis of the results with the use of histograms, intervals, other statistical indicators, received results of the simulation, etc.

Thus, the analysis of the best scientific practices on the implementation of the Monte Carlo method in the analysis of risks and prevention of reduction in the economic security level shows that many issues still remain unsolved in practice, which encourages to continue the research and scientific substantiation with the identification of 
advantages and disadvantages of the toolset of quantitative analysis of risks of the investment projects for the development of the country's infrastructure as well as its subsequence. When studying the peculiarities of application of Monte Carlo simulation method during the evaluation of the investment projects' risks, regarding the development of the country's infrastructure, it is necessary to clearly determine the process and principles of its conduction (Namey et. al., 2008). In particular, a special presentation of the risk analysis process with the use of the Monte Carlo method with the reflection of risk expression and calculation is given in Figure 2.

1. Bring in the primary data and parameters

2. Provided division

3. Take a random selection

4. Receive an outbound flow

5. Repeat the process a large number of times (from 1000 to 5000) for receiving the outbound division
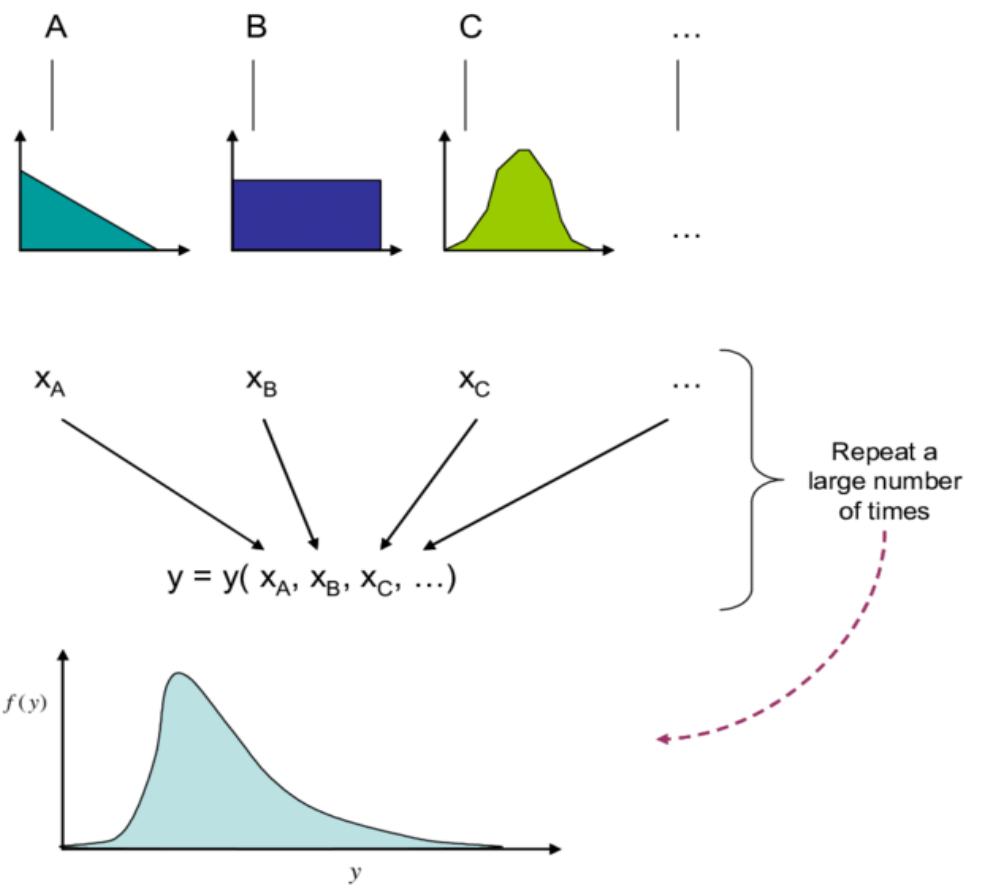

Figure 2. Process of Monte Carlo simulation Source: compiled by the author according to the data (Kroese et. al., 2011)

The corresponding distributions and correlations (interdependencies) are related to a huge base of data in the mathematical model. Herewith, the simulation is carried out through the use of a random number generator. In the result of contraction of probabilities, one receives cumulative graphs (often, the sensitivity analysis tools are included), and, therefore, the probabilities of the desired results can be assessed or calculated through their analysis. The Monte Carlo method is one of many uncertainty spreading analysis methods, in which the objective resides in the determination of the influence of the random variables, absence of knowledge, or errors on the sensitivity, performance, and reliability of a system that undergoes simulation. Thus, one conducts the choice of such a distribution for inputs that best matches already existing data or the one, which better reflects the actual information. Apart from that, one distinguishes the stochastic model (Fig. 3) and the deterministic model (Fig. 4). 


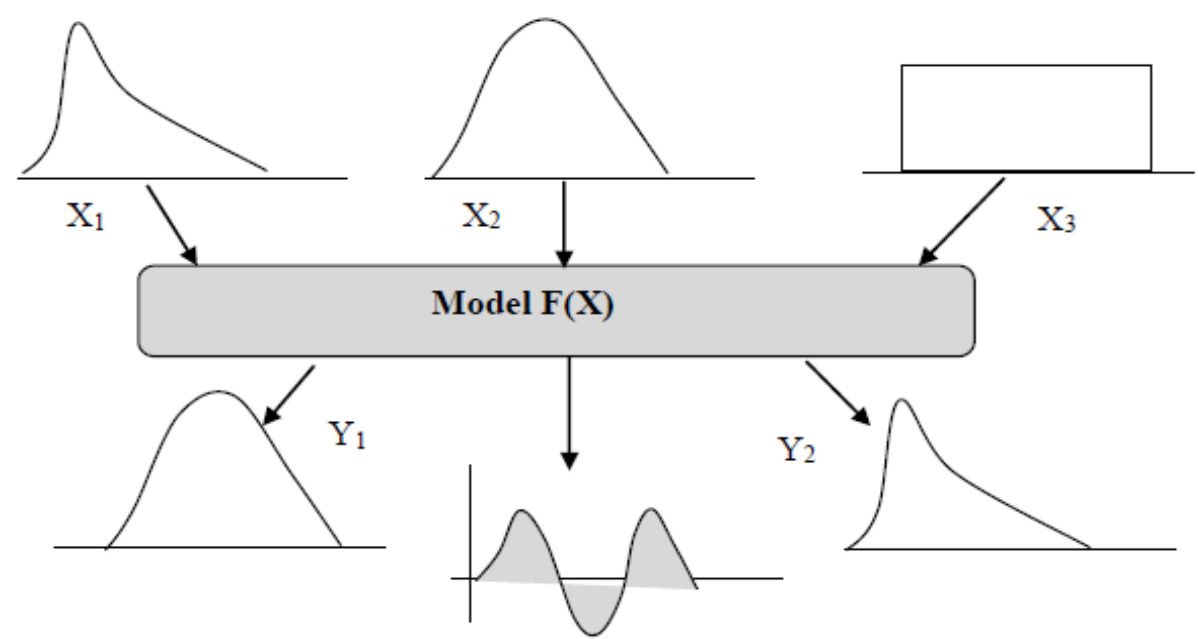

Figure 3. The main modeling principle upon the Monte Carlo method Source: compiled by the author according to the data (Robert and Casella 2004)

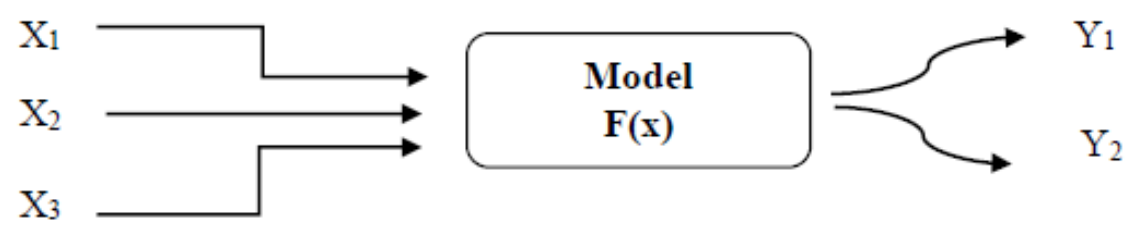

Figure 4. The principles of the deterministic model upon the Monte Carlo method Source: compiled by the authors according to the data (Robert and Casella 2004)

The fundamental difference between them resides in the facts that the parametric deterministic model establishes a set of input variables, reporting the set of output variables.

The uncertainty spreading, input random variables (described by a random distribution), and the result in the stochastic model will be random, and, as a rule, after the normal distribution. Monte Carlo simulation is a statistical method, combining the sensitivity analysis and probability distribution of explanatory variables (identified during the sensitivity analysis). We offer to present a simulation cycle in the Monte Carlo method using the following steps (Fig. 5).

When building a financial model, one should necessarily identify all significant variables first, which affect the risk of the national investment project. The number and the choice of variables depend on the type of investment and the range of conducted analyses (Kroese et. al., 2011). One often marks down as the random variables: the discount rate, the length of a life cycle, return on sales and operating expenses. This group should include the majority of variables as each consideration of a factor as a deterministic (outstanding) value is a simplification of the realm. As a consequence, at this stage, using a set of equations, describing the identified variables, one can build a single general model, serving for calculation of the measure of the investment efficiency (for example, the indicator $N P V$ ).

Within the framework of the second step, each explanatory variable is given probability distribution. In the case of a simulation, one faces great difficulties while determining the distribution of undefined variables and their corresponding probability. While conducting hypothetical distributions, one can use continuous distributions: normal distribution - the setting of a specific distribution requires the knowledge of the expected value and 
standard deviation of the distribution; uniform distribution - the establishment of a specific distribution requires awareness of the minimum and maximum distribution costs.

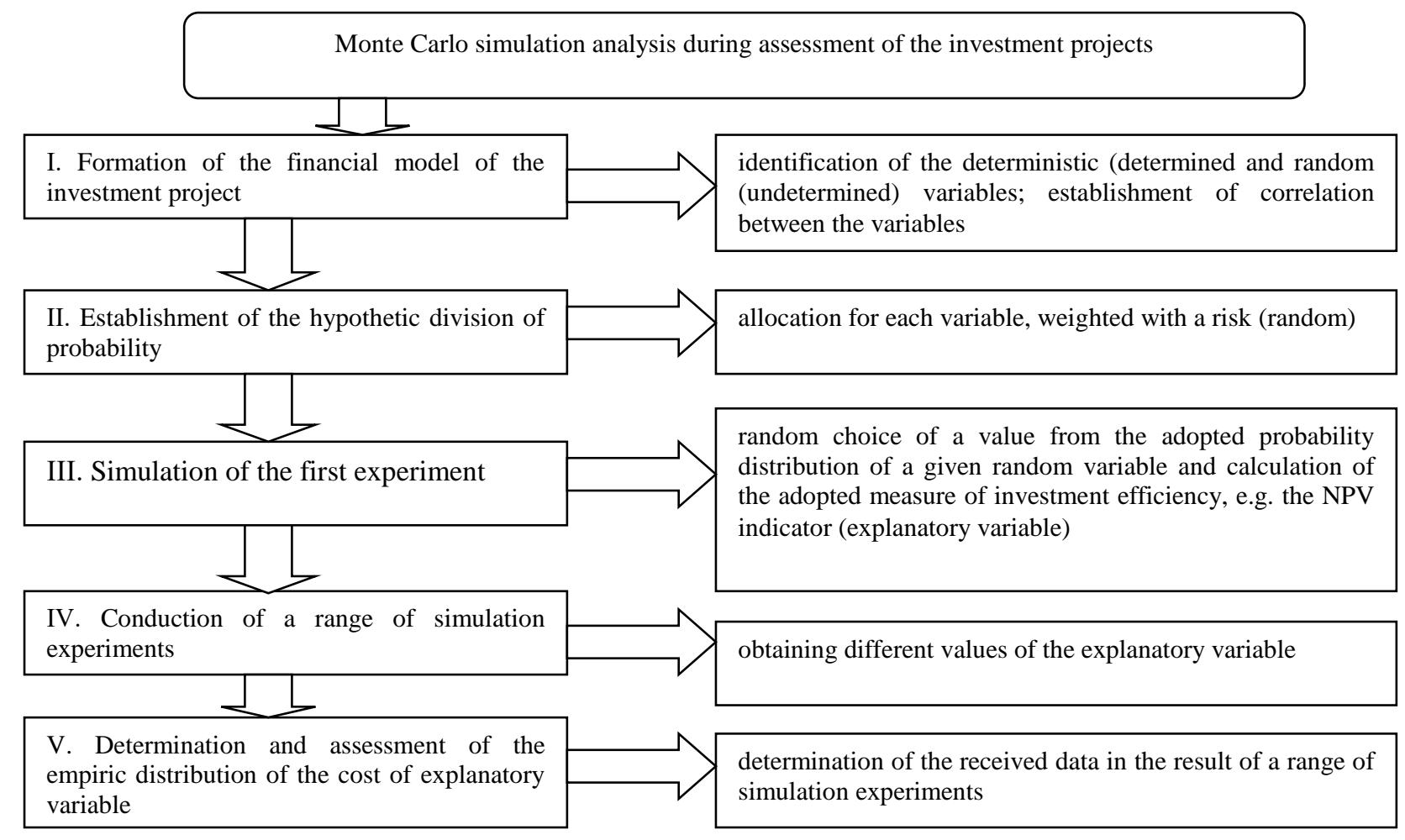

Figure 5. The procedure of the use of the Monte Carlo method for assessment of risks of the national investment projects at a given level of economic security

Source: designed by the authors

At the third stage, in one experiment, a random number is generated for each variable with the help of a computer program, which can be interpreted as an implementation, coming out of the accepted distribution. The selected values form the foundation for calculation of the flows of money, based on which, one calculates the $N P V$ and/or $I R R$ indicators. In contrast to the sensitivity analysis method, considering the explanatory variables separately, Monte Carlo simulation reviews these variables cumulatively, considering the relationship between them. The underestimation or ignoring of the correlation data reduces the weight of the obtained results as, in such a case, the analysis covers many unrealistic variants of the project, which, in its turn, can lead to incorrect decisions (Lumby, 1991).

At the fourth stage, the actions of the third stage are repeated many times (even several thousand times). Herewith, the accuracy of the result increases with the number of experiments.

In the lines of the fifth stage, one builds the distribution of probability $N P V$ and/or IRR and calculates their expected values and standard deviations. The final result of Monte Carlo simulation is the calculation of the probability of obtaining a positive $N P V$ and/or the internal rate of return $I R R$, the value of which is greater than the discount rate.

Thus, the generalization of conclusions concerning the practicability of application of Monte Carlo method and the method of historic simulations in assessment and minimizing of risks is formed in Table 1. 


\section{ENTREPRENEURSHIP AND SUSTAINABILITY ISSUES}

ISSN 2345-0282 (online) http://jssidoi.org/jesi/

2021 Volume 8 Number 4 (June)

http://doi.org/10.9770/jesi.2021.8.4(44)

Table 1. The peculiarities of application of the Monte Carlo method of simulations during the assessment and minimizing of risks of the investment projects in the coordinates of economic security

\begin{tabular}{|c|c|}
\hline Advantages & Disadvantages \\
\hline $\begin{array}{l}\text { Determines the probability of an event in tasks, where the complexity } \\
\text { of calculations increases to the dimension of the task exponentially. } \\
\text { High calculation accuracy. Provides a complete portfolio estimate. } \\
\text { Application of separate empirical and theoretical distribution } \\
\text { functions allows taking into account the effects of asymmetry and } \\
\text { "correlation breakdown" under market shocks. Does not require } \\
\text { significant amounts of empirical data. }\end{array}$ & $\begin{array}{l}\text { The simplicity and efficiency of the method are } \\
\text { detrimental to its accuracy. Due to the complexity and } \\
\text { number of calculations is significantly dependent on } \\
\text { technical equipment, high qualification of analysts, } \\
\text { significant time consumption. High risk of models } \\
\text { inadequacy. Low visibility and high complexity of } \\
\text { interpretation of the obtained assessment results. }\end{array}$ \\
\hline $\begin{array}{l}\text { Provides probabilical results, which not only show what can happen } \\
\text { but also reveal the level of occurrence possibility for a case or event. } \\
\text { Provides a graphic representation of the results. Provides a } \\
\text { vulnerability analysis. Analyzes scenarios. Investigates the } \\
\text { dependencies of the source data. Models the interconnected } \\
\text { relationships between input variables. }\end{array}$ & $\begin{array}{l}\text { Translates risk analysis by building possible result models, } \\
\text { changing different values of distribution plausibility. } \\
\text { Calculates results from the likelihood function using } \\
\text { different sets of values. Depending on the number of } \\
\text { unknown and established for them, groups can perform } \\
\text { tens of thousands of calculations. }\end{array}$ \\
\hline $\begin{array}{l}\text { It does not require any technical equipment. Intuitive ease of use and } \\
\text { clarity. Lack of additional theoretical simplifications and assumptions, } \\
\text { allows you to take into account the effects of "fat tails," asymmetries } \\
\text { and "correlation breakdown" under market shocks. Lack of model } \\
\text { risk. The simplicity of complete portfolio assessment. The empirical } \\
\text { distribution parameters can be used to build parametric models and } \\
\text { perform stochastic simulations. The empirical distribution can be } \\
\text { easily modified, which improves the accuracy of estimates. }\end{array}$ & $\begin{array}{l}\text { When different variables affect future results, the } \\
\text { effectiveness of the method decreases. The problem of } \\
\text { forming an effective sample. Based on the assumption that } \\
\text { past trends are a correct approximation of future market } \\
\text { performance dynamics. Requires significant amounts of } \\
\text { empirical data. Very sensitive to the choice of empirical } \\
\text { sample length. Demonstrates an "echo effect." Significant } \\
\text { decrease in accuracy of estimates at high confidence } \\
\text { levels. }\end{array}$ \\
\hline $\begin{array}{l}\text { Suitability for asymmetrical distributions; excellent applicability for } \\
\text { portfolios containing nonlinear instruments; simplicity and clarity of } \\
\text { calculations; absence of model risk; consideration of the entire set of } \\
\text { risks that caused changes in the price of assets for the analyzed } \\
\text { period. }\end{array}$ & $\begin{array}{l}\text { It is possible to err on the assumption that the past can be } \\
\text { an error in the future if the depth of the calculation period } \\
\text { is insufficient; there is no difference between the impact } \\
\text { on the result of old and recent observations; a large } \\
\text { number of calculations for large portfolios. }\end{array}$ \\
\hline
\end{tabular}

Source: designed by the authors

Thus, the simulation method of risk assessment is considered to be the most correct from the theoretic point of view, that is why it is not limited by a few variants of explanatory variables and, compared to the probabilisticstatistical methods, estimates the expected cost of E (NVP) in a more detailed manner. Through the use of simulation methods, it is relatively easy to read each type of correlation of explanatory variables as well as interhour correlations. However, in practice, selecting inherent distributions of explanatory variables and establishing distributions correlations between variables with uncertainty is a very difficult task. That is why one should mention that effective practical application of the Monte Carlo method in risk assessment of investment projects is complicated by the reasons for the determination of probability distribution of variables and correlation of distributions resulting from dependence between different factors.

Totality and inclusiveness are the features of modern economic risk. Therefore, economic risk is one of the fundamental definitions of modern economic theory and investment analysis. In practice, it is important to quantify the risks of investment projects, which determines the absolute or relative size of financial losses that threaten a potential investor in case of risk events. At the same time, the quantitative assessment of risk is objective, since it is based on a certain statistical basis.

In the scientific literature, the probability and statistics methods (probabilistic risk analysis, $P R A$ ) ground on the expanded assessment of critical flows of money, which is conducted with the use of sensibility analysis. These methods balance the main disadvantage of sensibility analysis - its deterministic nature (Tranfield et. al., 2003) note that the statistical and probabilistic method of risk assessment is based on the analysis of fluctuations of the 


\section{ENTREPRENEURSHIP AND SUSTAINABILITY ISSUES}

ISSN 2345-0282 (online) http://jssidoi.org/jesi/

2021 Volume 8 Number 4 (June)

http://doi.org/10.9770/jesi.2021.8.4(44)

estimated indicator for a certain period. Income, gross profit, net present value or net cash flow are used as such estimates in investment analysis. The application of the statistic-probabilistic method can be done in two directions: taking into account probabilistic estimates; without taking into account probabilistic estimates. The probability and statistics methods of risks assessment consider the use of positive random value as the criteria of such characteristics (the amount of damage) as the mathematical expectation; dispersion; the average deviation; the coefficient of variation (the standard relative deviation, which is defined as the average quadratic deviation, divided into the mathematical expectation, i. e. the standard deviation, expressed in fractions of the mathematical expectation); a linear combination of the mathematical expectation, and the average quadratic deviation; the mathematical expectation of the loss function, etc.

In the probabilistic-statistical methods, net flows of money are determined by the probabilistic method, i.e. one conducts several possible variants, and assigns a certain probability of occurrence, which makes it possible to carry out a risk assessment using statistical indicators of dispersion. Thus, these methods are based on probability and static assessment of risk, as well as determination of risk as a possible deviation from the expected value, in this case - from the result of the implementation of an investment project in the economic space, which is assessed with the use using various methods of efficiency assessment of investment projects. The risk of the investment project can be determined by estimating the dispersion of possible results around this central value, which in the risk concept is presented by the expected value (Asmussen and Glynn, 2007).

Regarding the economic tasks, methods of the probability theory are drawn to the determination of the values of the probability of occurrence of events and to selecting from possible events the most desirable scenario, based on the highest value of mathematical expectation, equal to the absolute value of evaluation of this event multiplied by the probability of its occurrence. The degree of risk is measured by two indicators: the average expected value and the fluctuation of the possible result. Random value dispersion and standard deviation, which are indicators of dispersion of a random variable around an average value, are most often used as indicators of risk associated with a certain investment project. The greater is the dispersion values, the higher are the risks (Inselbag and Kaufold, 1997). As a risk indicator within the limits of the probability and statistics methods, one also uses the variability coefficient, which is a relative indicator, allowing comparing the risks of several investment projects (Lefley, 1996). Thus, the conduction of probability and statistics risk assessment of an investment project should be based on relevant conceptual aspects (Fig. 6).

Under the probability and statistical assessment of risks of investment projects, regarding the country's infrastructure development and adherence to the proper level of economic security, one should use the method of net present value. Herewith, the $N P V$ calculations are treated as random variables, for which a certain probability of their occurrence can be set. Based on this, the expected net present value $E(N P V)$ is calculated, which is the absolute decisive criterion for this investment project. If the value of $E(N P V)$ is greater or equal to zero, then the project is effective. The scale of risk associated with this project is determined by the value of standard deviation $\sigma(N P V)$ and the shift coefficient $C(N P V)$ calculated on its basis - the lower is the value, the lower are the risks (Morrow et. al., 2007).

The relative decisive criterion, based on the presented statistical values, is based on maximizing the $E(N P V)$ value and minimizing the standard deviation. However, investment projects with a high expected value are also characterized by high values of dispersion indicators, which leads to the fact that an additional indicator is required for an unambiguous evaluation, which will make it possible to determine the risk that falls on the unit of expected value. This function is performed by the shift factor. Among the considered variants the best is the project, characterized by the lowest coefficient $C(N P V)$.

To estimate the expected value and risk of investment projects on the development of the country's infrastructure, it is necessary to establish the distribution of probabilities for explanatory variables determining the value of net 


\section{ENTREPRENEURSHIP AND SUSTAINABILITY ISSUES}

ISSN 2345-0282 (online) http://jssidoi.org/jesi/

2021 Volume 8 Number 4 (June)

http://doi.org/10.9770/jesi.2021.8.4(44)

cash flows. For each explanatory variable, it is necessary to set the distribution of the probability of forming their size at a certain expected level. Sometimes in practice, due to lack of relevant data on the probability distribution, a certain simplification is used, which mainly leads to the definition of several probability states for each explanatory variable adopted, as well as to the definition of probability of its obtaining. As or the example, it can be represented by the $N P V$ calculations for three different scenarios - optimistic, pessimistic, and the most real (average), the probability of occurrence of which can be determined, for example, as 0.7 - for the most real and 0.35 - for the optimistic and pessimistic. Nevertheless, the application of the restraint for the three main scenarios (optimistic, real, and pessimistic) is weighted by serious disadvantages (Ruback, 2002). One considers only a few specific variants of the project and assumes that undefined variables are correlated (all variables have simultaneously better or worse values).

The application of the probability and statistics methods is due to the interdependence between subsequent net flows of money. If the flows of money that will take place in the following years are independent (i.e. $N C F$, received in year $t$ does not affect the value of the net flow of money in the following year $(t+1)$ ), then the risks of the investment project are represented by the dispersion of random value and standard deviation. If vice versa, the net flows of money in year $t$ depend on the flows of money in the previous period $(t-1)$, then one conducts the calculation of the co-variation of net flows of money.

In the probabilistic sense, dispersion risk assessment resides in the assessment of several possible levels of flows of money for each period, as well as the determination of the probability of their manifestation in order to establish the expected balance of these flows $(N C F)$. Assuming that flows of money of a given investment project are independent, then the product of their manifestation probability determines the probability of manifestation of a certain balance of these flows - net flows of money.

The combination of possible flows of money forms the following scenarios, for which the $N V P$ indicators are calculated. Based on this, it is possible to determine the expected net present value, dispersions of random variables, standard deviations, and the variability coefficient (Maritan 2001). Thus, we offer the following procedure for calculation of the expected value $N V P$ of the investment project in the national economic space (Table 2). 


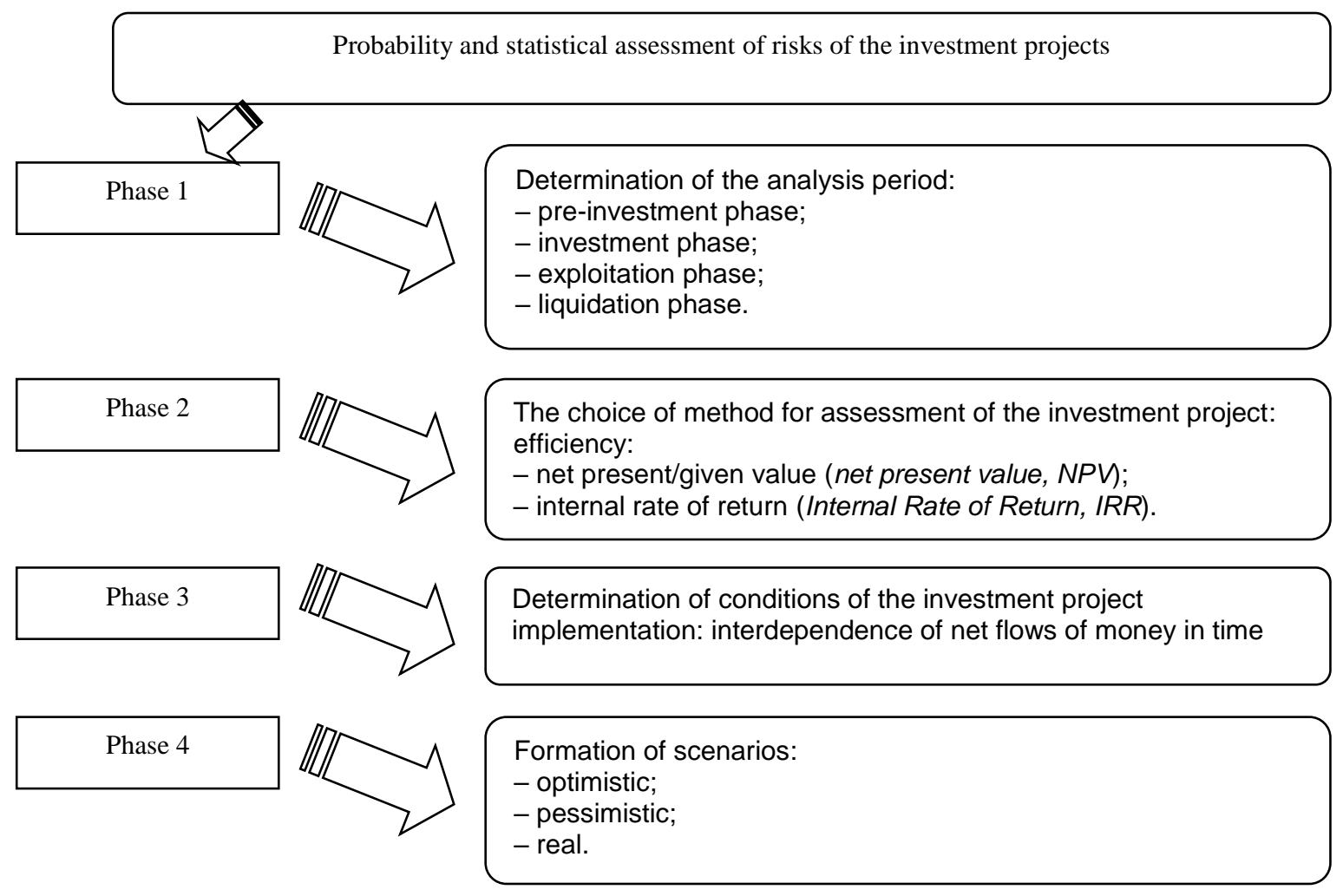

Figure 6. Conceptual principles of probability and statistical assessment of risks of the investment projects, regarding the country's infrastructure development at the given interval of economic security Source: designed by the authors

When determining the semi-dispersion risk, one should calculate the semi-dispersion of the net present value, semi-deviation, and the coefficient of semi- variability. A standard semi-deviation is an absolute risk measure, which can be used as a criterion in the absolute assessment. As a relative assessment criterion, it can be used when comparable projects have a similar level of expected values. Otherwise, the coefficient of semi-variability can be used as the relative risk measure. Semi-dispersion and standard deviation, as in the case with disperse risk, should be calculated based on less aggregate raw data, which is less pragmatic (Belli, 2001). 
Table 2. The procedure of calculation of the expected value $N V P$ of the investment projects within the national economic space and coordinates of economic security

\begin{tabular}{|c|c|c|c|}
\hline № & Indicator & Calculation formula & Commenting \\
\hline 1 & Net present value $E(N P V)$ & $E(N P V)=\sum_{i=1}^{n} p_{i} \times N P V_{i}$ & $\begin{array}{l}E(N P V)-\text { expected value, } N P V, \\
p_{i}-\text { probability of occurrence of the } i \text {-scenario, } \\
N P V_{i}-\text { cost of the } i \text {-scenario. }\end{array}$ \\
\hline 2 & Dispersion & $V(N P V)=\sum_{i=1}^{n} p_{i} \times\left[N P V_{i}-E(N P V)\right]^{2}$ & $\begin{array}{l}V(N P V) \text { - dispersion of } N P V, E(N P V) \\
\text { - expected value of } N P V, \\
p_{i} \text { - probability of occurrence of the } i \text {-scenario, } \\
N P V_{i} \text { - the } N P V \text { cost of the } i \text {-scenario. }\end{array}$ \\
\hline 3 & $\begin{array}{l}\text { The standard deviation of } \\
\text { dispersion }\end{array}$ & $\sigma N P V=\sqrt{V(N P V)}$ & $\begin{array}{l}\sigma N P V \text { - standard deviation of net present value, } \\
V(N P V) \text {-dispersion of the } N P V .\end{array}$ \\
\hline 4 & $\begin{array}{l}\text { Variability coefficient of } \\
\text { net present value } C(N P V)\end{array}$ & $C(N P V)=\frac{\sigma N P V}{E(N P V)}$ & $\begin{array}{l}C(N P V) \text { - variability coefficient, } \\
\sigma N P V \text { - standard deviation of net present value, } \\
E(N P V) \text { - expected value } N P V\end{array}$ \\
\hline 5 & $\begin{array}{l}\text { Semi-dispersion of net } \\
\text { present value }\end{array}$ & $V(N P V) \operatorname{sem}=\sum_{i=1}^{n} p_{i} \times h_{i}^{2}$ & $\begin{array}{l}V(N P V) \text { sem }- \text { semi-dispersion of } N P V \\
p_{i}-\text { - probability of occurrence of the } i \text {-scenario, } \\
h_{i}-\text { factor, depending on the deviation ratio }\end{array}$ \\
\hline 6 & & $h_{i}=\left\{\begin{array}{l}0 \leftrightarrow N P V_{i} \\
N P V_{i}-E(N P V) \leftrightarrow N P V\end{array}\right.$ & $\prec E(N P V)$ \\
\hline 7 & $\begin{array}{l}\text { Semi-deviation of standard } \\
N P V \text { value }\end{array}$ & $\sigma(N P V) \mathrm{sem}=\sqrt{V(N P V)} \mathrm{sem}$ & $\begin{array}{l}\sigma(N P V) \text { sem }- \text { standard semi-deviation of net } \\
\text { present value, } \\
V(N P V) \text { sem }\end{array}$ \\
\hline 8 & $\begin{array}{l}\text { Semi-variability } \\
\text { coefficient }\end{array}$ & $C(N P V) \operatorname{sem}=\frac{\sigma(N P V) s e m}{E(N P V) \operatorname{sem}}$ & $\begin{array}{l}C(N P V) \text { sem }_{-} \text {semi-variability coefficient, } \\
\sigma(N P V) \text { sem - standard semi-deviation of net } \\
\text { present value, } \\
E(N P V) \text { sem - expected semi-value of } N P V .\end{array}$ \\
\hline
\end{tabular}

The dispersion risk is calculated in practice during investment decision making. This results from the fact that the distribution of the probability of positive and negative deviations is mainly symmetrical. That is why the semidispersion may be equal to half of the dispersion, and, therefore, the application of these two methods may produce similar results. If the distribution is not symmetrical, then the value of semi-dispersion is less from the one of dispersion. At the same time, with the growth of this difference, the risk perceived in the negative vision decreases. In our opinion, the average quadratic deviation (standard deviation), the average absolute deviation, dispersion, and semi-dispersion are the common absolute indicators of assessing the risk level of real investment. These indicators ground on the deviations of individual values of a random average from an average measure. The application of indicators of the average quadratic deviation, dispersion, and semi-dispersion makes it possible to quantify the risk of several projects or several variants of one project. At the same time, a project with the minimum value of these indicators will be characterized by the lowest risk as it is for such a project that the scattering of random value around its average value will be the lowest (Francis \& Ibbotson, 2002).

Dispersion and semi-dispersion are the main probability and statistics methods of risk assessment. They are applied when the financial flows of the following years are independent. If the flows of money $\left(N C F_{t}\right)$ in year $\mathrm{t}$ 
are dependent on the financial flow for the previous period $(t-1)$, then to assess risk, one uses the covariance method. This method is associated with conditional probabilities of net flows of money. To put in in other words, if in year $t=1$ there are $i$-net cash flows $\left(N C F_{1 i}\right)$, and the indicators of probability $p_{1 i}$, corresponding to them, then in year $t=2$ there are $j$-net flows of money $\left(N C F_{2 j}\right)$ and indicators of probability $p_{2 j}$, corresponding to them. At the same time, this probability is of conditional nature and determined based on the criterion:

$$
p_{2 j}\left(\frac{N C F_{2 j}}{N C F_{1 i}}\right)=\frac{p\left(N C F_{1 i} \wedge N C F_{2 j}\right.}{p_{1 i}\left(N C F_{1 i}\right)}
$$

where: $p_{2 j}\left(\frac{N C F_{2 j}}{N C F_{1 i}}\right)$ - probability of the net flows of money $N C F_{2 j}$ under the condition of the previous appearance of net flows of money, $N C F_{1 i}, p_{2 j}$;

$p\left(N C F_{1 i} \wedge N C F_{2 j}\right.$ - probability of receiving the net flows of money $N C F_{1 i}$, in the year $t=1$ and $N C F_{2 j}$ the year $t=2$, or through their simultaneous manifestation.

Upon rearrangement, we get the example of the determination of occurrence probability in the year $t=1$ and the year $t=2$ for the net flows of money of $N C F_{1 i}$ and $N C F_{2 j}$ :

$$
p\left(N C F_{1 i} \wedge N C F_{2 j}=p_{1 i}\left(N C F_{1 i}\right) \times p_{2 j}\left(\frac{N C F_{2 j}}{N C F_{1 i}}\right)\right.
$$

After determination of conditional probabilities for the given net flows of money, through the use of examples with independent $N C F$ flows, the authors calculate the $N P V$ values for all possible combinations of the $N C F$ flows, and after that - statistical risk measures: expected net present value, standard deviation, and variability coefficient. The co-variance, which determines the dependence between the following net flows of money, can be calculated based on the following example:

$$
\operatorname{cov}\left(N C F_{1}, N C F_{2}\right)=\sum_{i=1}^{n} p_{i} \times\left(\left(N C F_{1 i}-E\left(N P V_{1}\right) \times\left(N C F_{2 i}-E\left(N P V_{2}\right)\right)\right.\right.
$$

where: $\operatorname{cov}\left(N C F_{1}, N C F_{2}\right)$ - covariance between net flows of money during the first and second year for the given investment project.

Covariance is a category, characterizing common changes for two random variables, in particular, if it: equal to zero $(\operatorname{cov}=0)$, then net flows of money are regarded as independent; greater than zero $(\operatorname{cov}>0)$, then the $N C F$ flowse are positively interdependent; less than zero $(\operatorname{cov}<0)$, then net flows of money are negatively interdependent. The use of the variation coefficient makes it is possible to compare oscillation of characteristics, expressed in different metric units. The variation coefficient can range from 0 to 1 . The greater is the variation coefficient, the greater is the fluctuation. The greater is the fluctuation, the higher is the risk (Gollier 2010). When choosing the best solution, it makes sense to use the rule of the optimal result variation, the key idea of which resides in the fact that from all possible solutions, one should choose the one, under which the probability of victory and loss for the same risk investment has a small gap, i.e. the smallest value of the average- quadratic deviation and variation. 


\section{ENTREPRENEURSHIP AND SUSTAINABILITY ISSUES}

ISSN 2345-0282 (online) http://jssidoi.org/jesi/

2021 Volume 8 Number 4 (June)

http://doi.org/10.9770/jesi.2021.8.4(44)

\section{Discussion}

Thus, the main advantage of the probability and statistics methods is that risk measurement is carried out with the use of objective measures - standard deviation and coefficient of variability. At the same time, these methods are characterized by certain disadvantages, in particular, the need for a significant number of assumptions as well as the complexity of the probability assessment of both net flows of money and particular scenarios. When using the offered approach for consideration of a risk factor during the assessment of efficiency and expediency of investment projects implementation, regarding the development of the country's infrastructure and advancement of the economic security level, an investor can make a reasonable choice of the best of them. This will improve the degree of justification of the investment decision making, reduce the probability of deterioration of the potential investor's financial state, and improve the correlation between the level of risk and expected return on implementation of investment projects, connected to the infrastructure development within the national economic space.

Thus, to activate the attraction of investments in the country's national economy, it makes sense to use efficient instruments of investment provision and consideration of the economic security components. Among modern instruments (stimuli) of investment provision of the national infrastructure development are the system of economic development monitoring, an effective credit policy, constructive interaction of local authorities with investors, government orders for products and services, advancement of the level of tax culture of the entities involved in investment activity, the mechanism of effective protection of the banking establishment rights under the long-term investment lending, etc.

The future research in this area can be formed in the expansion of the concept of investment provision of the national infrastructure development, the formation of the national investment policy considering the development of general infrastructure via the attraction and use of investments (including), based on strengthening the level of economic security. In order to achieve a high level of development of the general infrastructure of the country, a conceptual approach to the formation of the investment support of the infrastructure development can also be formed, which provides for conducting research in accordance with the logically related hypotheses regarding the interdependence of socio-economic situation in the country, development of its infrastructure, investment policy and economic security. To achieve a high level of development of common infrastructure of the country, one can also observe the formation of the conceptual approach to the formation of investment provision of the infrastructure development, including the implementation of research according to the given logically-related hypotheses, concerning the interdependence of socio-economic state in the country, development of its infrastructure, investment policy, and economic security. Such a conceptual approach to building the investment provision for infrastructure development can become the basis for scientific research, upon the results of which, one will substantiate the constructive toolkit for the development of investment provision of infrastructure development with consideration of the requirements of modern times.

\section{Conclusions}

Based on the results of the held research, the authors determined that the assessment of risks of the investment projects for the development of the country's infrastructure and provision of a high level of economic security can be carried out through the use of formatted economic and mathematical methods and models. Nonetheless, the article reveals that the most appropriate tool for it is the use of the Monte Carlo simulation analysis method, considering random variables, absence of knowledge or a mistake of the investors. In view of this, in their research, the authors formed the procedure of the Monte Carlo method use for assessment of the risks of an investment project, regarding the country's infrastructure development, covering five stages (formation of a 


\section{ENTREPRENEURSHIP AND SUSTAINABILITY ISSUES}

ISSN 2345-0282 (online) http://jssidoi.org/jesi/

2021 Volume 8 Number 4 (June)

http://doi.org/10.9770/jesi.2021.8.4(44)

financial model of an investment project, the establishment of a hypothetical probability distribution, simulation of the first experiment, conduction of a range of simulation experiments, determination and assessment of the empirical distribution of the value of the explanatory variable).

To use the method of probability and statistical assessment of risks of the investment projects for the development of the country's infrastructure, the authors offered to apply the method of net present value. Herewith, the $N V P$ calculations are interpreted as random variables, for which it is possible to set a certain probability of their occurrence. Based on the determined advantages of the selected methods, the authors formed the procedure for calculation of the expected $N V P$ value of the investment project, involving the calculation of such indicators as the net present value $E(N P V)$, dispersion, standard deviation of dispersion, change coefficient of the net present value $C(N P V)$, semi-dispersion of the net present value, semi-deviation of standard value of $N P V$, and coefficient of semi-variability. On the other hand, relevant assessment of the investment projects' risks for the development of the country's infrastructure is impossible without assessment of their efficiency, which is very often carried out through the use of the method of sensibility analysis of efficiency indicators. This method is one of the best known, easy to use, and makes it possible to determine those parameters, which are considered to be the riskiest ones for a given investment project. The sensibility analysis method also provides an opportunity to trace the influence of a specific parameter on the result, which can be both an indicator of the project efficiency in general ( $N P V, I R R, P I$, payback period), and an annual indicator of the project's activity.

\section{References}

Ackert, Lucy F., Deaves, Richard (2010). Behavioral Finance. South-Western Cengage Learning.

Alkaraan, F., Northcott, D. (2006). Strategic capital investment decision-making: A role for emergent analysis tools? A study of practice in large UK manufacturing companies. The British Accounting Review 38, 149-173

Arnold, Glen (2010). Investing: the definitive companion to investment and the financial markets. 2nd ed. Financial Times, Prentice Hall.

Asmussen, S., Glynn, P. W. (2007). Stochastic Simulation: Algorithms and Analysis. Springer-Verlag, New York, 2007.

Barnett, W. Steven, Milagros Nores. (2015). Investment and Productivity Arguments for ECCE. In P.T.M. Marope and Y. Kaga (eds), Investing against Evidence: The Global State of Early Childhood Care and Education, UNESCO.

Belli, P. (2001). Economic analysis of investment operations: Analytical tools and practical operations. Washington, DC: World Bank.

Campell, H., R. Brown. (2003). Benefit cost analysis, financial and economic appraisal using spreadsheet. Cambridge University Press.

Chambers, D.R., Harris, R.S., Pringle, J.J. (1982). Treatment of financing mix in analyzing investment opportunities. Financial Management, 8, 24-41.

Fabozzi, Frank J. (1999). Investment Management. 2nd. ed. Prentice Hall Inc.

Fishman, G. S. (1996). Monte Carlo: Concepts, Algorithms and Applications. Springer-Verlag, New York.

Francis, Jack C., Roger Ibbotson (2002). Investments: A Global Perspective. Prentice Hall Inc.

Gitman, Lawrence J., Joehnk, Michael D. (2008). Fundamentals of Investing. Pearson / Addison Wesley.

Gollier, Christian (2010). Expected net present value, expected net future value, and the Ramsey rule. Journal of Environmental Economics and Management, Vol. 59, 2142-2148. 


\section{ENTREPRENEURSHIP AND SUSTAINABILITY ISSUES}

ISSN 2345-0282 (online) http://jssidoi.org/jesi/

2021 Volume 8 Number 4 (June)

http://doi.org/10.9770/jesi.2021.8.4(44)

Inselbag, I., Kaufold, H. (1997). Two DCF approaches for valuing companies under alternative financing strategies (and how to choose between them). Journal of Applied Corporate Finance, 10, 114-122.

Jackson, J. (2010). Promoting energy efficiency investments with risk management decision tools. Energy Policy 38, $3865-3873$.

Kroese, D. P., Taimre T., and Botev, Z. I. (2011). Handbook of Monte Carlo Methods. John Wiley \& Sons, New York.

Lefley, F. (1996). The payback method for investment appraisal: A review and synthesis. International Journal of Production Economics 44, 207-224.

Lewis, D.L. (1999). Road user and mitigation costs in highway pavement projects. Washington, DC: Transportation Research Board, National Research Council.

Lumby, S., (1991). Investment Appraisal and Financing Decisions, A First Course in Financial Management, Forth Edition, Chapman \& Hall.

Maritan, C. A. (2001). Capital investment as investing in organizational capabilities: an empirically grounded process model. Academy of Management Journal 44(3), 513-531

Mazzanti, M., Mazzarano, M., Pronti, A., Quatrosi, M. (2020). Fiscal policies, public investments and wellbeing: mapping the evolution of the EU. Insights into Regional Development, 2(4), 725-749. http://doi.org/10.9770/IRD.2020.2.4(1)

Morrow, J.L., Sirmon, D.G., Hitt, M.A., and Holcomb, T.R. (2007). Creating value in the face of declining performance: Firm strategies and organizational recovery. Strategic Management Journal, 8(3), 271-283.

Namey, E., Guest, G., Thairu, L., Johnson, L. (2008). Data reduction techniques for large qualitative data sets. In Guest, G. and MacQueen, K. M. (Eds.) Handbook for team-based qualitative research. AltaMira Press.

Potts, D. (2002). Project planning and analysis for development. URL: https://www.rienner.com/title/Project Planning and Analysis for Development

Robert, C. P. and Casella, G. (2004). Monte Carlo Statistical Methods. Springer-Verlag, New York, second edition.

Ruback, R.S. (2002). Capital cash flows: a simple approach to valuing risky cash flows. Financial Management, 31, 85-103.

Tranfield, D., Denyer, D., Smart, P. (2003). Towards a Methodology for Developing Evidence Informed Management Knowledge by Means of Systematic Review. British Journal of Management 14: 207-222.

Wickson, F., Carew, A.L., Russell, A.W. (2006). Transdisciplinary research: characteristics, quandaries and qualities. Futures 38, 104610591

Wilmott, Paul (2009). Frequently Asked Questions in Quantitative Finance. 2nd ed. John Wiley and Sons, Ltd.

Yin, R. K. (2009). Case Study Research Design and Methods, 4th ed. Applied Social Research Methods Series, vol. 5. SAGE Publications. 
Lidiia KARPENKO, Doctor in Economics, Professor, Odessa Regional Institute for Public Administration of the National Academy for Public Administration under the President of Ukraine

ORCID ID: orcid.org/0000-0002-2888-2477

Mykola IZHA, Doctor of Political Sciences, Professor, Odessa Regional Institute for Public Administration of the National Academy for Public Administration under the President of Ukraine

ORCID ID: orcid.org/0000-0001-7221-4794

Iryna CHUNYTSKA, Doctor in Economics, Assistant Professor, University of the State Fiscal Service of Ukraine, Irpin ORCID ID: orcid.org/0000-0002-9718-1332

Andrii MAIEV, PhD in Public Administration, Associate Professor, Odessa Regional Institute for Public Administration of the National Academy for Public Administration under the President of Ukraine

ORCID ID: orcid.org/0000-0001-9333-2933

Kateryna HUNKO, PhD Student, University of the State Fiscal Service of Ukraine, Irpin

ORCID ID: orcid.org/0000-0002-1717-5937

Make your research more visible, join the Twitter account of ENTREPRENEURSHIP AND SUSTAINABILITY ISSUES: @Entrepr69728810

Copyright (C) 2021 by author(s) and VsI Entrepreneurship and Sustainability Center This work is licensed under the Creative Commons Attribution International License (CC BY). http://creativecommons.org/licenses/by/4.0/

(c) (7) Open Access 